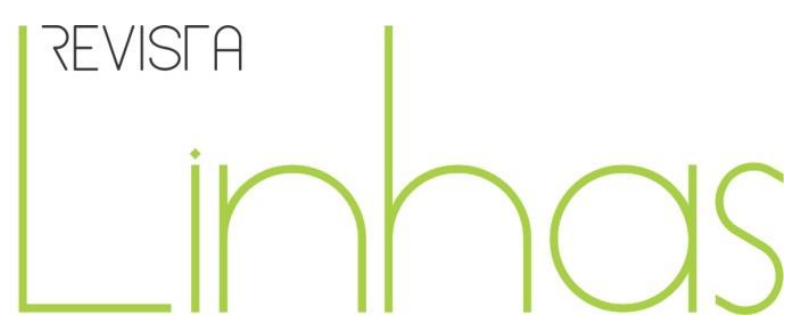

\title{
Interfaces entre interesses privados e públicos na educação escolar: o caso da Base Nacional Comum Curricular
}

\section{Resumo}

Este estudo tem o objetivo de analisar as abordagens que direcionam a Base Nacional Comum Curricular para a Educação Básica - BNCC (BRASIL, 2017 e 2018), verificando em que medida o documento atende aos interesses dos grupos privados. Este trabalho faz uma investigação das condições que motivaram a criação de um currículo que prevê uma padronização no alcance de todo o território nacional. Assim sendo, fundamentamos nosso estudo com pesquisa bibliográfica e documental de natureza básica e descritiva, considerando a abordagem conceitual crítica amparada no materialismo histórico-dialético. Ao tecer considerações, compreendendo as particularidades da educação pública, fica claro que a estratégia utilizada pelas elites é a formação do trabalhador com mão de obra barata e adaptável, tendo como foco a proliferação da ideologia e interesses da classe dominante e do acúmulo cada vez maior do capital.

Palavras-chave: Base Nacional Comum Curricular; grupos privados; educação pública.

\section{Rafaela Cristina Johann}

Universidade Estadual do Oeste do Paraná - UNIOESTE - Foz do

Iguaçu/PR - Brasil rafaelajohann@hotmail.com

\section{Júlia Malanchen}

Universidade Estadual do Oeste do Paraná - UNIOESTE - Foz do

Iguaçu/PR - Brasil

julia_malanchen@hotmail.com

\section{Para citar este artigo:}

JOHANN, Rafaela Cristina; MALANCHEN, Júlia. Interfaces entre interesses privados e públicos na educação escolar: o caso da Base Nacional Comum Curricular. Revista Linhas. Florianópolis, v. 22, n. 49, p. 132-155, maio/ago. 2021.

\section{DOI: $10.5965 / 1984723822492021132$}

http://dx.doi.org/10.5965/1984723822492021132 


\title{
Interfaces between private and public interests in school education: the case of the Common National Curricular Base
}

\begin{abstract}
This paper aims to analyze the approaches that guide the Common Curricular National Base for Basic Education - BNCC (BRAZIL, 2017 and 2018), verifying to what extent the document meets the interests of private groups. This study investigates the conditions that motivated the creation of a curriculum that foresees a standardization in the reach of the entire national territory. Therefore, we base our study with bibliographic and documentary research in a basic and descriptive form, considering the critical conceptual approach supported by historical-dialectical materialism. When making considerations, understanding the particularities of public education, it is clear that the strategy of the elites is the training of workers with cheap and adaptable labor, focusing on the proliferation of dominant class ideology and interests and the increasing accumulation of capital.
\end{abstract}

Keywords: Common Base National Curriculum; private groups; public education. 
A Base Nacional Comum Curricular (BNCC) é um documento de caráter normativo que determina os direitos de aprendizagens que devem ser contemplados durante a educação básica. Ela foi aprovada com o intuito de tornar-se uma referência nacional na construção dos currículos escolares e, para além disso, a BNCC, após sua aprovação (2017/2018), serviu também para subsidiar a reformulação das matrizes de avaliação de larga escala, alterando a política de formação inicial e continuada dos professores e, ainda, como medida para reformular materiais didáticos e demais cursos e kits pedagógicos a serem vendidos no mercado.

Considerando os princípios básicos da BNCC, corroboramos Santos e Orso (2020, p. 169), ao afirmarem que essa proposta é uma tentativa de chancelar uma política curricular "[...] esvaziada de conteúdos e pobre de conhecimentos, ao sabor das elites desejosas de manter os trabalhadores alienados, condição para perpetuação de seus privilégios". Assim, a partir de uma análise crítica, a BNCC é definida como uma representação hegemônica de educação e de escolarização (MACEDO, 2019).

De início, em alguns estudos já publicados, observamos que a BNCC tem negligenciado conhecimentos sistematizados em prol dos conhecimentos utilitários e cotidianos (MALANCHEN; MARSIGLIA et al. 2017; MATOS; ORSO, 2020; SAVIANI, 2020; ZANK, 2020). Essa manobra de diminuir do currículo das escolas os conhecimentos mais desenvolvidos, primando pelos conhecimentos da vida cotidiana, tem sido justificada como uma medida necessária para dispor aos alunos conhecimentos básicos às suas rotinas sociais e aos seus projetos de vida. Assim sendo, os conhecimentos de base teórica tendem a ocupar grande parte do tempo dos alunos e grande parte dos currículos escolares. À vista disso, um currículo mais pragmático é estimado, de modo que ele esteja focado no saber-fazer de cunho técnico e instrumental.

Com a previsão de ser implementada nas redes de ensino de todo o país no prazo de dois anos, contados a partir da data de sua homologação, o documento tem sido o objeto de estudo de várias pesquisas e tema de encontros e seminários voltados à abordagem escolar, desde, inclusive, muito antes de sua aprovação. A crítica em torno do texto se materializa pela afirmação de que ela vem para contemplar interesses da classe 
dominante, tendo como fundamentação a pedagogia das competências, uma vez que o documento estabelece dez competências gerais a serem desenvolvidas no processo de escolarização.

A União Nacional dos Dirigentes Municipais da Educação (UNDIME) e o Conselho Nacional de Secretários da Educação (CONSED), em parceira com o Ministério da Educação (MEC), União dos Conselhos Municipais de Educação (UNCME), o Fórum Nacional dos Conselhos Estaduais de Educação (FNCEE) e o grupo de agentes privados Movimento pela Base, lançaram o Guia de Implementação da BNCC'1, com o intuito de contribuir com a proposta de reorganização curricular dos estados, municípios e do Distrito Federal em regime de colaboração. Na mesma medida, foram anunciados programas de apoio para a implementação da Base nas redes de ensino, como é o caso do ProBNCC, reconhecido pela Portaria $\mathrm{n}^{\circ} 331$, de 5 de abril de $2018^{2}$, indicando diretrizes, parâmetros e critérios para colocar em pleno funcionamento a BNCC por meio da oferta de assistência financeira e técnica ao Distrito Federal, estados e municípios. Acrescenta-se que a UNDIME, o CONSED e os grupos privados mostram-se mais dedicados ao processo de implementação da Base do que o próprio MEC (MACEDO, 2019).

É importante frisar que, ao situarmos a discussão em torno de uma educação pública de qualidade, não estamos nos fazendo valer da tese advogada pelos neoliberais, que entendem que a escola deve ser direcionada sob os preceitos privatistas para avançar em rankings internacionais e superar as expectativas do mercado econômico. Acreditamos que, para que os avanços na educação escolar sejam materializados, é preciso investimento em políticas públicas educacionais comprometidas com a formação das novas gerações e dedicadas a disponibilizar a esses alunos o acesso aos campos da ciência, da arte e da filosofia, como forma de ofertar aos sujeitos o desenvolvimento nas suas máximas possibilidades.

Todavia, ao reforçar o viés dominante, a educação dos filhos da classe trabalhadora é comprometida, haja vista que as condições de vida e de acesso da maioria dos alunos não são consideradas no debate sobre o acolhimento de medidas que romantizam a meritocracia como uma condição necessária à natureza humana para a

\footnotetext{
${ }^{1}$ Acessar guia em: <https://implementacaobncc.com.br/>. Último acesso realizado em: 21/05/2021.

${ }^{2}$ Disponível em: https://abmes.org.br/legislacoes/detalhe/2431 Último acesso realizado em: 21/05/2021.
} 
garantia do sucesso no mercado de trabalho. Sem embargo, sustentamos a tese de que esse discurso falacioso é empregado na sociedade como forma de camuflar as responsabilidades dos governantes em contemplar o direito de acesso dos alunos a uma educação pública de qualidade.

Foi pensando na formação em níveis mais elevados para o conjunto dos homens que esta pesquisa se debruçou na análise conceitual da Base Nacional Comum Curricular (BNCC, 2017/2018), que teve a intensa participação dos grupos privados na sua elaboração desde as primeiras discussões. Com isso, nos propomos a verificar quais as expectativas do grupo privado diante da educação pública brasileira a partir das orientações dos organismos internacionais.

Para dar sequência, destacamos que este artigo é fundamentado em pesquisa bibliográfica e documental, de natureza básica e descritiva, cuja abordagem conceitual está amparada no materialismo histórico-dialético.

\section{0 arranjo neoliberal e as abordagens capitalistas na educação escolar: considerações preliminares}

O debate que antecipa as discussões sobre as políticas educacionais na atualidade deve considerar a existência de projetos neoliberais que cerceiam a educação escolar no Brasil, pincipalmente a partir de 1990, período em que o país era governado por Fernando Henrique Cardoso (FHC) ${ }^{3}$.

O neoliberalismo apresenta-se como uma hegemonia dominante dedicada a estabelecer projeções político-ideológicas para promover ações necessárias ao desenvolvimento global do capital. Consoante a isso, se manifesta como uma força catalisadora que objetiva a perpetuação do sistema social atual e movimenta os bastidores dos processos de desmonte da educação pública, aliando-se aos grupos privatistas.

Cumpre assinalar que a partir de 1980, com o progresso da industrialização, da globalização e das bases tecnológicas, o Estado passa por uma série de reformas com o objetivo de amenizar as crises existentes da época, favorecendo os ideais privatistas. À

${ }^{3}$ Fernando Henrique Cardoso foi um dos fundadores do Partido Social Democrático Brasileiro (PSDB). 
vista disso, as discussões sobre o papel do Estado assumiam centralidade entre os integrantes dos grupos nacionais e internacionais do mercado econômico. A Reforma do Estado contribuiu de forma significativa para os avanços da globalização. Nesse contexto, o neoliberalismo se fortalece porque está articulado a políticas globais que atendem às demandas das grandes corporações, conferindo vantagens ao mercado e interferindo consideravelmente nas políticas que resguardam os serviços sociais.

Com tal concepção, o Estado é o principal inimigo da geração da qualidade social, pois é um mau gestor (Schuler, 2017) e impede o funcionamento da lógica do mercado, devendo, portanto, ser reduzido a um mínimo e - mais importante - sem possibilidade de interferir no mercado, o que atrapalharia sua lógica natural. (FREITAS, 2018, p. 31)

O processo de descentralização é, em grande medida, o ponto inicial para que seja priorizada a adoção de concepções privatistas nas proposições educativas; diante disso, seus defensores advogam pela fiscalização, gerenciamento e execução de projetos sob o argumento de que estariam contribuindo com a autonomia das escolas. Nesse sentido, vale ressaltar que as reformas estão alinhadas a aparatos ideológicos de poder, que determinam meios e estratégias para o progresso do sistema capitalista a partir de mudanças administrativas.

Diante disso, é relevante pontuar que a educação, no Brasil, passou a ser organizada com base em uma perspectiva econômica mundial. Sob essa mesma base, a Organização das Nações Unidas para a Educação, Ciência e Cultura (UNESCO), na década de 1990, contribuiu de modo significativo para que houvesse a expansão de orientações nos países em desenvolvimento, colaborando com a aceitação e a permanência das reformas na educação.

Entretanto, se sobressai o protagonismo do Banco Mundial (BM) e do Fundo Monetário Internacional (FMI) enquanto principais organismos internacionais responsáveis por nortear as políticas públicas de educação nos países em desenvolvimento. De acordo com Robertoson e Verger (2012) o BM, o FMI, a Organização para a Cooperação do Desenvolvimento Econômico (OCDE) e a United States Agency for Inter-national Development (Usaid) atuaram para fortalecer o livre mercado e expandir as 
atividades dos setores privados por meio de políticas de ajustes estruturais. Não por acaso,

[...] contribuem para essa construção, transformando "constatações", "avaliações" e "comparações" em oportunidades para produzir um discurso global que tira sua força justamente de sua dimensão planetária. Nesse plano, as organizações internacionais, além de sua força financeira, tendem a representar cada vez mais um papel de centralização política e normatização simbólica. Ainda que trocas entre sistemas escolares não sejam novidade, nunca se esteve tão claro que um modelo hegemônico pode tornar-se o horizonte comum dos sistemas de ensino nacionais, e sua força impositiva vem justamente do seu caráter globalizado. (LAVAL, 2019, p. 19)

A prescrição de orientações ao Brasil e o apoio a políticas públicas que viabilizam os interesses do capital a partir do BM é uma realidade ainda presente. Nessa acepção, tendo como iniciativa a redução da pobreza em países em desenvolvimento, o BM realizava a transição não só de financiamentos, como também de pesquisas, levantamentos de dados e demais orientações para desenhar a política pública desses países com o propósito de elevar o desenvolvimento econômico e social de seus territórios (DECKER; EVANGELISTA, 2019).

Contudo, por deter o poder de aprovar empréstimos para vários territórios, principalmente para os de países subdesenvolvidos, a garantia da negociação desses trâmites com os governos é firmada, em grande medida, por meio de acordos que seguem parâmetros semelhantes a uma troca de favores. Consoante a isso, ao lançar a aprovação de financiamentos aos governos, o BM reivindica a participação ativa para contribuir com as tomadas de decisões governamentais dos seus devedores. Posto isso, vale considerar que:

O reformismo neoliberal é, portanto, entendido como a diminuição e a restrição das áreas de atuação do Estado, com vistas à alocação das riquezas produzidas por determinado país prioritariamente ao agrado e serviço do rentismo do capital financeiro internacional. Em países em desenvolvimento, o controle inflacionário e o sistema da dívida pública são mais sensivelmente ainda aos pilares dessa estrutura galgada pelo neoliberalismo. Desse modo, para além de uma doutrina econômica, o neoliberalismo começou a se tornar também uma força ideológica hegemônica no centro do capitalismo global a partir dos anos 1980 e, de certa forma, imposta e exportada como modelo para as regiões periféricas do capitalismo, fossem esses países recém-redemocratizados como na América do Sul, bem como nações descolonizadas na Ásia e na 
África, a ponto de muitos dos governantes eleitos sob plataformas socialdemocratas ou mesmo de esquerda tendo se inclinado, em algum grau, aos pilares da hegemonia da doutrina neoliberal. (COSTA; SILVA, 2019, p. 5)

Nesse cenário, as raízes do capitalismo são devidamente implementadas e normatizadas pelos reformistas, privilegiando o mercado competitivo e econômico. Não obstante, a agenda global materializada pelo BM confere à educação escolar a “[...] responsabilidade pelo crescimento econômico e a redução da pobreza, legitimando o desenvolvimento da escolarização numa perspectiva meritocrática, instrumental e de formação de capital humano para atendimentos às demandas do capital” (DECKER; EVANGELISTA, 2019, p. 4).

Em níveis ascendentes, o setor privado vai conquistando espaço nas negociações nacionais e internacionais, fragilizando os dispositivos de ordem democrática e afetando os direitos básicos da classe trabalhadora pela redução do dever do Estado, retrocedendo, inclusive, nos avanços já alcançados e aprofundando o "[...] desmonte dos serviços públicos, de privatizações e de entreguismo do patrimônio nacional ao rentismo e ao capital financeiro internacional" (LAVOURA; ALVES; SANTOS JR., 2020, p. 554). Sob essas circunstâncias, oculta-se das documentações a preocupação com as possíveis consequências de medidas impositivas decorrentes desses movimentos, sendo a progressão da desigualdade e a precarização do ensino duas das suas maiores respostas.

Em uma análise feita nas proposições do BM, Decker e Evangelista (2019, p. 5) destacam o esforço do organismo em difundir a relação entre a qualidade da educação e do aprendizado com mecanismos pautados na especificidade econômica; assim, sob esses moldes, a educação contribuiria para a economia "[...] via formação e conformação da classe trabalhadora."

No campo das relações entre capital e trabalho, a perpetuação de privilégios das grandes elites tem encaminhado à educação escolar a responsabilidade de formar trabalhadores eficientes e com fácil capacidade adaptativa para lidar com situações práticas do cotidiano. Para tais fins, a padronização da formação dos sujeitos se faz necessária no sentido de contribuir com o lucro do capital em detrimento da força de trabalho dos assalariados. Portanto, cumpre assinalar que expandir intenções aos 
processos formativos é uma pretensão empresarial para formar um sujeito conformado com a condição de explorado nesta sociedade, ao mesmo tempo em que o capital avança em suas formas mais desiguais.

Assim sendo, este projeto dominante estima, por meio do currículo escolar, a possibilidade de colocar em prática algumas de suas intenções. Logo, a partir dessas considerações, podemos então destacar a formulação da Base Nacional Comum Curricular como sendo um desses projetos que se articula intimamente com os preceitos da classe empresarial, uma vez que, desde as suas primeiras discussões, contou com representantes de grupos privados no planejamento de suas especificidades.

\section{Base Nacional Comum Curricular e os monopólios privatistas}

Prevista de forma indireta na Constituição Federal de 1988, a necessidade de uma BNCC é respaldada no artigo 210 dessa lei, o qual dispõe que "[...] serão fixados conteúdos mínimos para o ensino fundamental, de maneira a assegurar a educação básica comum e o respeito aos valores culturais e artísticos, nacionais e regionais" (BRASIL, 1988). Consoante a isso, a Lei de Diretrizes e Bases da Educação (LDB 9394/96) também indica a precisão de uma base nacional comum no artigo 26 e no artigo 64, indicando que:

Os currículos da educação infantil, do ensino fundamental e do ensino médio devem ter uma base nacional comum, a ser complementada, em cada sistema de ensino e em cada estabelecimento escolar por uma parte diversificada, exigida pelas características regionais e locais da sociedade, da cultura, da economia e dos educandos. (BRASIL, 1996, art. 26)

A formação de profissionais de educação para administração, planejamento, inspeção, supervisão e orientação educacional para a educação básica, será feita em cursos de graduação em pedagogia ou em nível de pós-graduação, a critério da instituição de ensino, garantida nesta formação a base comum nacional. (BRASIL, 1996, art. 64)

De modo equivalente, é importante destacar que os Parâmetros Curriculares Nacionais (PCNs) de 1997 foram objetivados visando o alcance nacional para nortear a construção dos currículos escolares; entretanto, sua concepção nuclear buscava a 
superação das formas científicas de conhecimento, atendendo à demanda da vida em

sociedade. O documento também analisava a adoção de avaliações de larga escala "[...] num pretenso processo de melhoria educacional, que começa pelo "final”, ou seja, pela avaliação" (CORRÊA; MORGADO, 2018, p. 4). Outro ponto fulcral na discussão sobre os PCNs se aplica na forma de orientar o trabalho docente, tendo em vista que o documento serviria como um instrumento para “[...] verificar se a capacitação dos docentes estava alinhada com a formação dos alunos, de acordo com as exigências expostas no próprio documento e também cobradas nas avaliações nacionais" (BRANCO; IWASSE; BRANCO, 2017, p. 9272).

Mesmo representando as forças hierárquicas e contando com o apoio do BM e o FMI, diante das limitações do documento e de abordagens evasivas, o PCN, enquanto normativa obrigatória, não foi aceito pela comunidade escolar e tampouco por especialistas que se debruçaram a estudá-lo. Assim sendo, o texto perdeu força de lei e tornou-se apenas um parâmetro.

A partir do governo de Luiz Inácio Lula da Silva (Lula), com mandato ativo entre 2003 e 2010, uma nova equipe passou a constituir o Ministério da Educação (MEC). No comando do MEC estava o ex-ministro Fernando Haddad, que estruturou as novas Diretrizes Curriculares Nacionais (DCNs), sendo aprovadas nas seguintes formas: Diretrizes Curriculares Nacionais para a Educação Infantil (BRASIL, DCN, 2009); Diretrizes Curriculares Nacionais Gerais para a Educação Básica (BRASIL, DCN, 2010); Diretrizes Curriculares Nacionais para o Ensino Fundamental de Nove Anos (BRASIL, DCN, 2010); Diretrizes Curriculares Nacionais para o Ensino Médio (BRASIL, DCN, 2012) e as Diretrizes Curriculares Nacionais para temas específicos (BRASIL, DCN, 2013). Em termos gerais, a construção das DCNs (2010) (Parecer CNE/CEB n 7/2010) contou com a participação ampla da comunidade escolar, diferentemente do processo adotado na formulação dos PCNs.

Nas investigações de Tarlau e Moeller (2020) está descrita a existência de uma “versão zero" da BNCC, materializada entre os anos de 2009 e 2014, por meio de conferências, grupos de estudos e debates que tinham o objetivo de propor a redução das desigualdades na aprendizagem, considerando as diferenças regionais. 
O forte embasamento histórico e filosófico do documento foi o suficiente para gerar uma movimentação contrária do setor empresarial ao andamento da proposta. $\mathrm{O}$ Movimento Todos pela Base e a Fundação Lemann ${ }^{4}$ foram os principais protagonistas dedicados a minimizar o conteúdo daquela matéria, pois advogavam por uma proposta mais "prática". O documento, por sua vez, nunca foi divulgado pelo MEC e, de acordo com Tarlau e Moeller (2020), foi o Movimento Todos pela Base quem se esforçou para impedir a sua divulgação pública.

Dando sequência, em discussão realizada no dia 25 de junho de 2014, foi aprovado Plano Nacional de Educação (PNE) a partir da Lei n 13.005, com vigência de dez anos a contar da data de aprovação (2014-2024). O PNE contempla vinte metas voltadas aos diferentes níveis da educação, sendo destacadas quatro que são voltadas à construção de uma BNCC, a saber: metas 2, 3, 7 e 15.

Com efeito, em 2015, durante o governo de Dilma Rousseff, foi divulgada a primeira versão da Base contemplando as etapas da educação infantil, do ensino fundamental e do ensino médio. Cumpre assinalar que, para a construção da BNCC, foi constituída pelo MEC uma comissão de especialistas por meio da Portaria $n^{\circ}$ 592, de 17 de julho de 20155, sendo formada por 116 membros, incluindo representantes da União Nacional dos Dirigentes Municipais da Educação (UNDIME), do Conselho Nacional de Secretários da Educação (CONSED), de Universidades Estaduais e do Distrito Federal, bem como representantes da Secretaria de Educação Básica (SEB).

Para além desses agentes, o que chama atenção é o elevado número de representantes do setor privado na participação da formulação da proposta, o Movimento Todos pela Base e o grupo Todos pela Educação ${ }^{6}$, por exemplo, somam um

\footnotetext{
${ }^{4}$ Fundada pelo economista e empresário Jorge Paulo Lemann, cuja fortuna é avaliada em 91 bilhões de reais segundo a Forbes (2020). De acordo com o site Infooney, Lemann investiu em empresas como Telemar, Gafisa e ALL e, com a fundação do fundo $3 G$ Capital, comprou as redes Burger King, Tim Hortons, Popeyes e Heinz. Ademais, a fonte também indica que Lemann é o idealizador de três entidades filantrópicas: Fundação Estudar, Fundação Lemann e Instituto Tênis. Ver mais em: <https://www.infomoney.com.br/perfil/jorge-paulo-lemann/>. Acesso em: 26/05/2021.

5 Disponível em: <http://portal.mec.gov.br/index.php?option=com_docman\&view=download\&alias=21361port-592-bnc-21-set-2015-pdf\&ltemid=30192>. Acesso em: 20/05/2021.

${ }^{6}$ De acordo com o site, o grupo Todos pela Educação é uma organização da sociedade civil, sem fins lucrativos, sem relações governamentais e apartidário, financiado pelo setor privado para "qualificar o debate e articular com o setor público". Um dos principais Sócios Fundadores do Todos pela Educação é Jorge Paulo Lemann. Ver em: <https://todospelaeducacao.org.br/downloads/socios-fundadores/>. Acesso
} 
conjunto vasto de instituições privadas. De acordo com Tarlau e Moeller (2020, p. 579), em 2016, o Movimento pela Base tinha em sua composição 65 membros, entre eles “[...] 30 lideranças de diferentes fundamentações, 19 funcionários governamentais, oito pesquisadores de universidades e sete políticos". Portanto, fizeram parte da trajetória da BNCC, empresas e fundações como: Abave, Cenpec, Comunidade Educativa Cedac, Fundação Lemann, Fundação Maria Cecilia Souto Vidigal, Fundação Roberto Marinho, Instituto Ayrton Senna, Instituto Inspirare, Instituto Natura, Unibanco, Itaú, entre outros (QUEM, 2020).

Diante disso, quando lançada para a consulta pública, entre setembro de 2015 e março de 2016, a BNCC recebeu cerca de 12 milhões de contribuições, que, mesmo entre diversas críticas sobre o processo, resultou, em 2016, na segunda versão do documento. Nesse ponto, é válido destacar que ambas as versões tinham como cerne os direitos de aprendizagens a serem desenvolvidos na educação básica.

Para essa análise, é imprescindível resgatar um acontecimento histórico que marcou o ano de 2016 no Brasil, o processo de impeachment contra Dilma Rousseff, que colocou na presidência Michel Temer (PMDB)7. Por consequência disso e, mais precisamente, com a ascensão de Temer, vários setores que compõem o aparelho governamental foram alterados, promovendo trocas de presidências e de membros em vários ministérios, inclusive no MEC, para o qual foi designado José Mendonça Bezerra Filho. Nesse cenário, vários nomes ligados ao PMDB e ao $\mathrm{DEM}^{8}$ foram indicados. Na mesma medida, ampliou-se a passagem de representantes de grupos empresariais às pastas públicas.

Além de Bezerra Filho, é relevante dar destaque a mais dois nomes, sendo o de Maria Helena Guimarães de Castro (PSDB) ${ }^{9}$, que foi nomeada para ocupar a Secretaria Executiva do MEC, e Maria Inês Fini (PSDB), que passou a gerir o Instituto Nacional de Estudos e Pesquisas (INEP). Destacamos, nesse ponto, a passagem de Maria Helena Guimarães como presidente o INEP entre os anos de 1995 e 2002, advogando pelas

\footnotetext{
em: 26/05/2012.

7 Partido do Movimento Democrático Brasileiro.

${ }^{8}$ Partido Democratas.

9 Partido da Social Democracia Brasileira.
} 
avaliações de larga escala e pela construção dos PCNs; já Maria Inês Fini também atuou no governo $\mathrm{FHC}^{10}$, na diretoria de avaliação para a certificação de competências (19962002).

Aqui, vale indagar sobre a seguinte questão: o que levaria o governo a nomear três nomes que defendem reformas que privilegiam o setor empresarial no âmbito da educação? De acordo com Marsiglia et al. (2017), a resposta consiste na possibilidade de inserir os preceitos neoliberais nas políticas educacionais como forma de priorizar os interesses privatistas.

Doravante, a partir da Portaria $\mathrm{n}^{\circ} 790$ publicada pelo MEC, é instituído o Comitê Gestor, para contribuir com a implementação da BNCC e da Reforma do Ensino Médio, cuja função é "“[...] acompanhar o processo de discussão da segunda versão preliminar da BNCC, encaminhar sua proposta final e propor subsídios para a Reforma do Ensino Médio" (AGUIAR, 2018, p. 730).

Com a segunda versão disponibilizada em maio de 2016, a consulta pública se estendeu a audiências públicas realizadas em cinco regiões diferentes do país, organizadas em datas diversas pela Consed e pela Undime, as quais contaram com a participação de cerca de 9 mil educadores com o propósito de encaminhar ao Conselho Nacional de Educação (CNE) documentos com orientações e sugestões desenvolvidas junto aos demais participantes para serem analisadas e consideradas na construção da terceira versão da BNCC.

O que causou estranheza é o fato de que a BNCC, em sua terceira versão, foi aprovada no dia 15 de dezembro de forma aligeirada, negando as sugestões encaminhadas ao Comitê Gestor do $\mathrm{MEC}^{11}$ e não incluindo a parte do Ensino Médio na base, sendo ela aprovada somente em 2018, após a publicação da Reforma do Ensino Médio por meio da Medida Provisória (MP 746/2016) ${ }^{12}$.

Feito isso, a BNCC aprovada continua contemplando os direitos de aprendizagens, entretanto, o fundamento central do documento passa agora a ser direcionado por competências e habilidades que devem ser desenvolvidas durante toda a educação básica.

\footnotetext{
${ }^{10}$ Fernando Henrique Cardoso.

${ }^{11}$ Resultados das audiências públicas e de pedidos de associações educacionais e demais entidades.

${ }^{12}$ Disponível em: <https://legis.senado.leg.br/norma/553876/publicacao/15634025>. Acesso em: 20/05/2021.
} 
Eis a condição que prevê que a educação escolar deva caminhar lado a lado com os interesses dos grupos privados.

A pedagogia das competências que está presente na BNCC (2017/2018) é uma referência conceitual alicerçada aos interesses do capital. Respaldada em Philipe Perrenoud, essa corrente pedagógica busca desenvolver a “[...] capacidade de agir eficazmente em determinado tipo de situação, apoiando-se em conhecimentos, mas sem limitar-se a eles" (PERRENOUD, 1999, p. 7). A Base deve, portanto, contemplar conteúdos que permitam o desenvolvimento de competências para que o aluno desenvolva condições básicas e necessárias ao mercado de trabalho, na mesma medida em que passa a ter acesso a aprendizagens úteis ao seu cotidiano.

Em síntese, a pedagogia das competências acolhe parâmetros da vida cotidiana para organizar a proposta curricular, propagando a ideia de que a carga de conhecimentos científicos dentro dos currículos escolares é desnecessária para a formação dos alunos, entendendo que é preciso focar no "saber-fazer", o que contribui significativamente para os avanços no setor econômico. Dadas essas considerações, vale ressaltar que a pedagogia das competências é enquadrada por Newton Duarte (2001) em um conjunto de pedagogias que seguem a linha do "aprender a aprender" ${ }^{13}$, sendo esse conjunto, um reflexo da escola nova.

É sob esse ideário que a escola passa a ser convocada para formar indivíduos autônomos, competitivos, eficientes e competentes para atuar na construção e consolidação da denominada sociedade do conhecimento ou da informação. A "pedagogia das competências" passa a ser evocada como fundamento epistemológico da formação escolar, em todos os níveis de ensino, sendo, portanto, a medida do sucesso ou fracasso do indivíduo. (MALANCHEN; SANTOS, 2020, p. 9)

Na esteira dessas ideias, o observado é o esforço em naturalizar o projeto burguês a partir de um discurso sedutor que está associado à proposição neoliberal, fragilizando o desenvolvimento dos alunos e não permitindo a aproximação aos conhecimentos mais desenvolvidos, uma vez que objetiva a fragmentação dos currículos escolares, abrigando

\footnotetext{
${ }^{13}$ Considerando os limites deste artigo, não nos debruçamos na discussão sobre as pedagogias do Aprender a Aprender, mas deixamos a indicação das seguintes obras para o aprofundamento do tema a quem interessar: Vigotski e o Aprender a Aprender: crítica às apropriações neoliberais e pós-modernas da teoria vigotskiana (DUARTE, 2011) e História das Ideias Pedagógicas no Brasil (SAVIANI, 2019).
} 
as formas mais pragmáticas de conhecimentos. Ademais, cabe considerar que essa perspectiva busca a formação do homem adaptado, conformado com o sistema social vigente.

Ao optar por usar o conceito de competência como articulador da BNCC, - MEC/CNE se refere "a OCDE extensivamente como fonte de conhecimento, visando tanto à validação quanto à legitimação" (MAUSETHAGEN, 2013, p.165 apud MACEDO, 2019, p. 49) de suas políticas, como ocorre em diversos outros países. A definição de competência da BNCC, reproduzida no material destinado aos docentes (nas páginas do MEC e do Movimento pela Base), guarda aproximações com as propostas da Organização: "a mobilização de conhecimentos, habilidades, atitudes e valores para resolver demandas complexas da vida cotidiana, do exercício pleno da cidadania e do mundo do trabalho." (MACEDO, 2019, p. 49)

Para as elites, o controle sobre o que se ensina nas escolas é importante no sentido de moldar o trabalhador das novas gerações a partir da sua escolarização; assim, não por acaso, o currículo tem sido disputado em diversos momentos da história. Todavia, o que presenciamos na atualidade é a existência de uma força catalisadora dominante, que busca se apropriar de todo e qualquer mecanismo que possibilite à classe trabalhadora a sua emancipação.

Cumpre assinalar que a BNCC (2017/2018) dá subsídios para as avalições internacionais, indicando, inclusive, a remodelagem das matrizes de referências dos processos avaliativos no Brasil, preocupando-se com rankings internacionais, seguindo os indicativos da Organização para a Cooperação e Desenvolvimento Econômico (OCDE) que tem o Programa Internacional de Avaliação de Alunos (PISA) como base.

Evidencia-se, então, a constituição de um exército composto por sistemas, programas e instrumentos que realizarão avaliações e comparações entre países. A padronização, materializada nos dados de testes internacionais, como o Programa Internacional de Avaliação de Estudantes (PISA), e nos inúmeros gráficos e tabelas provenientes da Organização para a Cooperação e Desenvolvimento Econômico (OCDE), objetiva estabelecer um ideário de metas educacionais que não condizem com a materialidade brasileira e negligenciam qualquer análise que não seja estritamente de cunho quantitativo. (DECKER; EVANGELISTA, 2019, p. 16) 
A OCDE tem propagado ações com vieses voltados à produtividade econômica em

nível mundial, disseminando a formação para o empreendedorismo, favorecendo e estimulando o estreitamento das relações entre os governos e as avaliações internacionais. Outrossim, mesmo compreendendo que há necessidade de investimentos na escola pública, a OCDE sublinha que o foco deve ser mantido no desenvolvimento econômico. Ademais, as medidas com as quais são fomentadas as formas de pensar a educação a partir dos preceitos empresariais são imbuídas em uma forte concepção de competitividade para o mercado de trabalho. Isso tem afunilado a educação dos filhos da classe trabalhadora, pois o plano burguês não acolhe medidas que favoreçam a emancipação dessa classe, mas sim medidas que a mantêm estagnada em suas condições, a serviço do capital.

Nesse sentido, a mercantilização do ensino tende a desencadear procedimentos de concorrências generalizadas, não somente entre escolas da rede pública e privada, mas, similarmente, entre as próprias escolas públicas. Laval assevera que,

[...] nesse caso, o principal fator não é a intervenção direta do capital, mas a introdução da competição entre os "consumidores da escola", uma competição que supostamente trará mais eficiência. O neoliberalismo escolar resultou, na verdade, numa verdadeira guerra entre classes para entrar nas "boas escolas" de um sistema escolar e universitário cada vez mais hierarquizado e desigualitário. (LAVAL, 2019, p. 13)

Grosso modo, o currículo da educação básica tem desencadeado conflitos entre setor público e setor privado. Com a agenda política que regulamenta o Estado mínimo, os interesses dos grupos privados são considerados em detrimento dos interesses da escola pública, homogeneizando um projeto de nação a partir dos preceitos burgueses, invalidando a autonomia das instituições, modificando a gestão, o currículo, a formação inicial e continuada dos professores, os processos avaliativos, entre outros fatores.

Para os empresários, a definição de padrões comuns é algo importante na formação de uma mão de obra com requisitos básicos para o trabalho. Essa medida abre um grande campo de investimento e de interesse do setor privado ao se relacionar, entre outros, com a produção de material didático e com a oferta de cursos para a 
formação docente e de gestores, movimentando ainda uma grande parcela de recursos públicos. (SANTOS; PEREIRA, 2016, p. 288)

As forças majoritárias do capital internacional aprofundam projetos voltados ao mundo globalizado, orientando a escola a partir dos parâmetros de “[...] uma indústria de serviços de educação a ser governada, como parte da construção de uma sociedade de mercado" (ROBERTSON; VERGER, 2012, p. 1135).

A atuação mínima do Estado nas tomadas de decisões sobre a educação tem oportunizado a perpetuação de interesses, articulando os processos de financiamento e gerenciamento da educação escolar, tornando predominante a lógica do capital. A exemplo, está a Fundação Lemann, que acompanhou o processo de construção da BNCC desde as primeiras discussões, financiando eventos, pesquisas, viagens e outros serviços que contribuíram com o andamento do projeto de formulação de uma base nacional comum para os currículos escolares, compelindo estratégias de advocacy. A fundação tem articulado seus projetos junto ao Movimento pela Base, além de ser a principal organização dentro do grupo Todos pela Educação, defendendo uma formação técnica para o mercado de trabalho e para o exercício da cidadania.

O Movimento pela Base e a Fundação Lemann investiram fortemente em estudos que se dedicavam a analisar os sistemas educacionais de outros países, com efeito, encaminhavam orientações para serem consideradas dentro do texto da BNCC. Nesse sentido, para fortalecer a aceitação das suas propostas, os grupos empresariais encontraram apoio na grande mídia para propagar a ideia entre as massas e entre a comunidade escolar, não no sentido de divulgar o cerne da matéria, mas no sentido de convencer o público em geral sobre a necessidade dessa BNCC a partir do modo como ela estava sendo proposta.

Cássio (2019) assevera que a Fundação Lemann fez uso dos meios de comunicação para propagar a BNCC através de um discurso utópico, adotando uma estratégia midiática para uma cobertura positiva sobre a base. O autor destaca que o mercado jornalístico produz "[...] matérias favoráveis sobre a Base, bem como a mídia especializada em economia: o Jornal Valor Econômico e as revistas Exame, IstoÉ Dinheiro e Época Negócios" (CÁSSIO, 2019, p. 15, grifo do autor). Assim, de modo a acrescentar, destacamos a Revista 
Nova Escola, porque ela intensifica a aproximação da Fundação Lemann com a rede de professores, pois, para além das matérias jornalísticas que buscam convencer sobre a necessidade da Base nos moldes em que foi aprovada, a revista ainda disponibiliza planos de aulas que orientam os professores para o uso da BNCC, e com a contribuição do Google.org, os materiais alcançam seus maiores clientes, os professores (CÁSSIO, 2019).

Na mesma medida, o autor afirma que a fundação uniu um conjunto de agentes políticos, especialistas e apoiadores do projeto para sair em defesa da BNCC, estendendo o diálogo inclusive ao CONSED e à UNDIME. Nesse cenário, outra estratégia adotada pela fundação foi voltada à disseminação da ideia persuasiva de que a Base era um projeto "apartidário", sendo observada como uma política voltada especificamente aos interesses dos alunos. Contudo, observa-se que tal estratégia foi utilizada para evitar conflitos políticos e a associação do documento a determinados partidos (TARLAU; MOELLER, 2020).

Para concluir, nessa acepção, asseguramos que a movimentação estratégica dos privatistas está em confronto com os interesses da classe trabalhadora, produzindo a pauperização das ordens democráticas pela ânsia de uma política educacional esvaziada. Nesse sentido, o setor privado busca naturalizar a concepção mercadológica na formação da classe trabalhadora, realçando as ambiguidades voltadas ao desenvolvimento econômico no sentido de preservar os privilégios das grandes elites.

\section{Conclusões}

A propagação ideológica do ideário neoliberal tem intensificado o processo de reestruturação produtiva preconizada pelo mercado, como forma de alavancar o acúmulo de capital. As alianças entre o grupo empresarial e os defensores neoliberais se reconhecem no interesse de articular uma formação para a classe trabalhadora centrada no empreendedorismo, na competitividade, na capacidade de se estabelecer uma harmonia social, e outros aspectos.

Ao sistema financeiro, não interessa que o aluno aprenda conhecimentos mais desenvolvidos porque ele não prima pelo conhecimento enquanto valor humano; na contramão disso, vê por meio de alguns conhecimentos, a oportunidade de produzir 
riquezas. Nessa propositura, a boa ciência não é aquela que promove uma formação crítica emancipadora, mas sim, aquela que produz novas formas de exploração do homem e da natureza gerando grandes lucros ao capital.

O conhecimento é aquilo que humaniza, e, nesse sentido, precisa ser apropriado pelos alunos em condições objetivas, não bastando somente ao professor a sua apropriação. É preciso torná-lo acessível aos sujeitos, estabelecendo a dialética entre a área do conhecimento e o trabalho educativo, sendo ele o ato de "[...] produzir, direta e intencionalmente, em cada indivíduo singular, a humanidade que é produzida histórica e coletivamente pelo conjunto dos homens" (SAVIANI, 2013, p. 13).

As tentativas de padronização e de flexibilização curricular atingem diretamente o trabalho docente, haja vista que essa atividade fica subordinada a provas estandardizadas, relacionadas, ainda, com os interesses do capital que primam pela produtividade e pela eficiência dos sistemas de ensino.

Com a BNCC, o que percebemos é a tentativa de camuflar a participação da comunidade escolar na tomada de decisões voltadas à educação, desse modo, a autonomia das escolas e dos professores são desconsideradas, privilegiando as opiniões e interesses de técnicos e especialistas indicados por representantes dos privatistas. É relevante pontuar que o ranqueamento das escolas e a produção da forma competitiva do ser dentro dos espaços escolares têm feito progredir as abordagens mercadológicas que ilustram a educação como um empreendimento e um campo de negócios.

A estratégia adotada pelos privatistas é a de focar em um ensino pautado em habilidades técnicas e instrumentais alicerçadas aos interesses do capital, que se propõe a formar um sujeito meramente adaptável, que não tenha capacidade crítica de questionar a dinâmica desta sociedade, formando indivíduos despolitizados.

Nesse sentido, cumpre assinalar que a BNCC, tendo como cerne uma corrente hegemônica materializada na pedagogia das competências, tem contribuído de forma ampla com os preceitos do capital. Essa abordagem por competências tem sido apropriada para justificar a defesa de um currículo flexibilizado, tão ambicionado pelo grupo privado, pois é composto de conhecimentos que se fazem úteis à vida cotidiana nas suas formas imediatas, distanciando-se dos conhecimentos sistematizados, que são 
aqueles capazes de promover o desenvolvimento de raciocínios complexos e de uma visão de mundo crítica, tão necessária ao desenvolvimento humano nas suas formas mais evoluídas.

A ideologia acolhida por essas concepções hegemônicas decreta o poder da elite sobre os processos formativos de uma classe dominada, ou seja, as perspectivas de avanço do grupo operário ficam mantidas sob o controle dos donos dos meios de produção até que uma nova sociedade seja configurada, nesse caso, a sociedade socialista.

Não obstante, é importante que a classe trabalhadora se reconheça na luta contra a hegemonia dominante, compreendendo que ela é a responsável pelo desmonte dos serviços públicos destinados aos que mais precisam. É nesse sentido que Laval (2019) ressalta que o laço entre os professores é fundamental, para que, unidos, tenham acesso aos movimentos da ordem educacional em nível mundial, e assim consigam fortalecer a luta e a resistência para o avanço de uma escola democrática que não coloque em risco a autonomia dos professores e pesquisadores. 


\section{Referências}

AGUIAR, Marcia Angela da Silva. Política Nacional e a Base Nacional Comum Curricular: o processo de formação em questão. Revista Currículo sem Fronteiras, [S.I]. 18, n. 3, p. 722 738, set./dez. 2018. Disponível em:

http://www.curriculosemfronteiras.org/vol18isszarticles/aguiar.html. Acesso em: 06 dez. 2019.

BRANCO, Emerson Pererira; IWASSE, Lilian Fávaro Alegrâncio; BRANCO, Alessandra Batista de Godoi. Os parâmetros curriculares nacionais e a organização curricular. In: CONGRESSO NACIONAL DE EDUCAÇÃO - EDUCERE, 13., Curitiba, 2017. Anais [...]. Curitiba: Puc-PR, 2017. Disponível em:

https://educere.bruc.com.br/arquivo/pdf2017/23681_11755.pdf. Acesso em: 21 maio 2021

BRASIL. MEC. Base Nacional Comum Curricular. Brasília, DF: MEC, 2017.

BRASIL. Constituição da República Federativa do Brasil de 1988. Brasília: Presidência da República, 1988. Disponível em:

https://www2.senado.leg.br/bdsf/bitstream/handle/id/518231/CF88_Livro_EC91_2016.pdf. Acesso em: 25 maio 2021.

BRASIL. Diretrizes Curriculares Nacionais Gerais da Educação Básica. Brasília: MEC: CEB: DICEI, 2013.

BRASIL. Resolução $\mathbf{n}^{\circ}$ 7, de 14 de dezembro. Fixa as diretrizes curriculares nacionais para 0 ensino fundamental de 9 (nove) anos. Brasília: MEC: CNE: CEB, 2010. Disponível em: http://portal.mec.gov.br/dmdocuments/rcebo07_10.pdf. Acesso em: 26 maio 2021.

BRASIL. Resolução CNE/CEB No 2, de 30 de janeiro. Define as diretrizes curriculares nacionais para o ensino médio. Brasília: CNE: CEB, 2012. Disponível em:

http://www.crmariocovas.sp.gov.br/Downloads/ccs/concurso_2013/PDFs/resol_federal_2 _12.pdf Acesso em: 26 maio 2012.

BRASIL. Resolução CNE/CEB nº 5, de 17 de dezembro. Fixa as diretrizes curriculares nacionais para a educação infantil. Brasília, DF: [s.n.], 2009. Disponível em: http://www.crmariocovas.sp.gov.br/Downloads/ccs/concurso_2013/PDFs/resol_federal_5 _09.pdf Acesso em: 26 maio 2021

BRASIL. Resolução $\mathbf{n}^{\circ} \mathbf{4}$, de $\mathbf{1 3}$ de julho. Define as diretrizes curriculares nacionais para a educação básica. Brasília: MEC: CNE: CEB, 2010. Disponível em: http://portal.mec.gov.br/dmdocuments/rcebo04_10.pdf. Acesso em: 26 maio 2021.

BRASIL. Guia de implementação da base nacional comum curricular: orientações para o processo de implementação da BNCC. Brasília: MEC; CONSED; UNDIME; UNCME; FNCEE. 2020. Disponível em: https://implementacaobncc.com.br/wpcontent/uploads/2020/02/guia_implementacao_bncc_atualizado_2020.pdf. Acesso em: 26 jan. 2021 
BRASIL. Lei de diretrizes e bases da educação. Lei n 9394/1996. Brasília: Senado Federal, Coordenação de Edições Técnicas, 2017.

BRASIL. MEC. Portaria $\mathbf{n}^{\circ}$ 790, de 27 de julho de 2016. Institui o comitê gestor da base nacional comum curricular e reforma do ensino médio. Brasília: MEC, 2016. Disponível em: https://www.cnte.org.br/images/stories/2016/Comite_BNCC_Portaria_790_27_07_2016.pd f. Acesso em: 21/05/2021.

BRASIL. Parâmetros curriculares nacionais. Brasília: MEC, 1997.

CÁSSIO, Fernando. A BNCC como política educacional. In: CÁSSIO, Fernando; CATELLI JR., Roberto. Educação é a Base? 23 educadores discutem a BNCC. São Paulo: Ação Educativa. 2019.

CORRÊA, Adriana; MORGADO, José Carlos. A construção da base nacional comum curricular no brasil: tensões e desafios. In: COLÓQUIO LUSO-BRASILEIRO DE EDUCAÇÃO COBEDUCA, 4, 2018, Braga. Anais [...]. Florianópolis: Udesc, 2018. v. 3. Disponível em: http://www.revistas.udesc.br/index.php/colbeduca/article/view/12979 Acesso em: 21 maio 2021.

COSTA, Marilda de Oliveira; SILVA, Leonardo Almeida da. Educação e democracia: base nacional comum curricular e novo ensino médio sob a ótica de entidades acadêmicas da área educacional. Revista Brasileira de Educação, Rio de Janeiro, v. 24, e240047, 2019. Disponível em: http://www.scielo.br/pdf/rbedu/v24/1809-449X-rbedu-24-e240047.pdf. Acesso em: 18 fev. 2020.

DECKER, Aline; EVANGELISTA, Olinda. Educação na lógica do Banco Mundial: formação para a sociabilidade capitalista. Roteiro, Santa Catarina, v. 44, n. 3, p.1-24, set./dez. 2019. Disponível em: https://portalperiodicos.unoesc.edu.br/roteiro/article/view/23206.

Acesso em: 21 maio 2021.

DUARTE, Newton. As pedagogias do "aprender a aprender" e algumas ilusões da assim chamada sociedade do conhecimento. Revista Brasileira de Educação, Rio de Janeiro, n. 18, p. 35-40, 2001. Disponível em: http://www.scielo.br/pdf/rbedu/n18/n18a04.pdf. Acesso em: 30 set. 2020.

DUARTE, Newton. Vigotski e o “aprender a aprender": crítica às apropriações neoliberais e pós-modernas da teoria vigotskiana. 5.ed. Campinas: Autores Associados, 2011.

FREITAS, Luiz Carlos de. A reforma empresarial da educação: nova direita, velhas ideias. 1. ed. São Paulo: Expressão Popular, 2018.

LAVAL, Christian. A escola não é uma empresa: o neoliberalismo em ataque ao ensino público. 1. ed. São Paulo: Boitempo, 2019. 
LAVOURA, Tiago Nicola; ALVES, Melina Silva; SANTOS JUNIOR, Claudio Lira. Política de formação de professores e da destruição das forças produtivas: BNC-formação em debate. Revista Práxis Educacional, Vitória da Conquista, v. 16, n. 37, p. 553-577, 2020. Edição Especial. Disponível em:

http://periodicos2.uesb.br/index.php/praxis/article/view/6405. Acesso em: 07 abr. 2020.

MACEDO, Elisabeth Fernandes de. Fazendo a Base virar realidade: competências e o germe da comparação. Revista Retratos da Escola, Brasília, v. 13, n. 25, p. 39-58, jan./maio 2019. Disponível em: http://retratosdaescola.emnuvens.com.br/rde/article/view/967. Acesso em: 22 maio 2021.

MALANCHEN, Julia; SANTOS, Silvia Alves dos. Políticas e reformas curriculares no Brasil: perspectiva de currículo a partir da pedagogia histórico-crítica versus a base nacional comum curricular e a pedagogia das competências. Revista HistedBr On-line. Campinas, v. 20, e020017, 2020. Disponível em:

https://periodicos.sbu.unicamp.br/ojs/index.php/histedbr/article/view/8656967 Acesso em: 22 maio 2021.

MARSIGLIA, Ana Carolina Galvão; et al. A base nacional comum curricular: um novo episódio de esvaziamento da escola no Brasil. Germinal: Marxismo e Educação em Debate, Salvador, v. 9, n. 1, p. 107-121, 2017. Disponível em: https://portalseer.ufba.br/index.php/revistagerminal/article/view/21835. Acesso em: 22 jun. 2019.

PERRENOUD, Philippe. Construir competências desde a escola. Tradução: Bruno Charles Magne. Porto Alegre: Artmed, 1999.

QUEM somos. Movimento pela base nacional comum, [S.I.], 2020. Disponível em: http://movimentopelabase.org.br/quem-somos/. Acesso em: 11 fev. 2020.

ROBERTSON, Susan; VERGER, Antoni. A origem das parcerias público-privada na governança global da educação. Educação e Sociedade, Campinas, v. 33, n. 121, p. 11331156, out./dez. 2012. Disponível em: http://www.scielo.br/pdf/es/v33n121/a12v33n121.pdf. Acesso em: 21 fev. 2020.

SANTOS, Lucíola de Castro Paixão; PEREIRA, Julio Emílio Diniz. Tentativas de padronização do currículo e da formação de professores no Brasil. Cad. Cedes, Campinas: São Paulo, v. 36, n. 100, p. 281-300, set./ dez. 2016. Disponível em: https://www.scielo.br/j/ccedes/a/SqHHMdWVCV9Fwpgq4GRnb7B/abstract/?lang=pt Acesso em: 22 maio 2021.

SANTOS, Silvia Alves dos; ORSO, Paulino José. Base Nacional Comum Curricular - uma base sem base: o ataque à escola pública. In: MALANCHEN, Julia; MATOS, Neide da Silveira Duarte; ORSO, Paulino José (orgs.). A pedagogia histórico-crítica, as políticas educacionais e a base nacional comum curricular. Campinas: Autores Associados, 2020. p. 161-178. 
SAVIANI, Dermeval. Educação escolar, currículo e sociedade: o problema da Base

Nacional Comum Curricular. In: MALANCHEN, Julia; MATOS, Neide da Silveira Duarte.; ORSO, Paulino José (orgs.). A pedagogia histórico-crítica, as políticas educacionais e a base nacional comum curricular. Campinas: Autores Associados, 2020. p. 7-30.

SAVIANI, Dermeval. História das ideias pedagógicas no Brasil. 5. ed. Campinas: Autores Associados, 2019.

SAVIANI, Dermeval. Pedagogia histórico-crítica: primeiras aproximações. 11. ed. Campinas: Autores Associados, 2013.

TARLAU, Rebecca; MOELLER, Kathryn. O consenso do Filantropia: como a fundação privada estabeleceu a BNCC no Brasil. Revista Currículo sem Fronteiras, [S.I.], v. 20, n. 2, p. 553-603, 2020. Disponível em:

https://www.curriculosemfronteiras.org/vol2oisszarticles/tarlau-moeller.pdf. Acesso em: 26 jan. 2021.

ZANK, Débora Cristine Trindade. Base nacional comum curricular e o "novo" ensino médio: análise a partir dos pressupostos teóricos da pedagogia histórico-crítica. programa de pós-graduação UNIOESTE - Foz do Iguaçu: área de concentração: ciências, tecnologia, linguagens e cultura. [S.I.: s.n.], 2020.

Recebido em: 17/03/2021 Aprovado em: 31/05/2021

Universidade do Estado de Santa Catarina - UDESC Programa de Pós-Graduação em Educação - PPGE Revista Linhas Volume 22 - Número 49 - Ano 2021 revistalinhas@gmail.com 